\title{
ELECTRICAL STIMULATION IN THE TREATMENT OF CONGENITAL PSEUDARTHROSIS OF THE TIBIA
}

\author{
DENNIS C. PATERSON, ROBERT B. SIMONIS \\ From Adelaide Children's Hospital, Adelaide, and the Rowley Bristow Orthopaedic Hospital, Pyrford
}

\begin{abstract}
A treatment regime using electrical stimulation in association with a variety of surgical procedures has improved the prognosis in congenital pseudarthrosis of the tibia-one of the most challenging of all orthopaedic disorders.

The technique consists of correction of the tibial deformity, intramedullary fixation and cancellous bone grafting, augmented by electrical stimulation using an implanted bone-growth stimulator. Experience with 27 pseudarthroses in 25 patients is presented; of those, 20 have joined. The cases have been reviewed and the causes of failure analysed. These results offer encouragement to the orthopaedic surgeon treating this difficult condition.
\end{abstract}

The treatment of congenital pseudarthrosis of the tibia is, in many cases, unsuccessful. Morrissy, Riseborough and Hall (1981), reviewing different types of bone grafting procedures performed on $\mathbf{4 0}$ children with this condition, showed that only the Farmer procedure (composite skin and bone pedicle from the other leg) gave a reasonable union rate $(53 \%)$. All the other procedures they discussed produced such a low union rate that they could not be considered acceptable: onlay grafts had a $12.5 \%$ union rate, bypass procedures $7 \%$, Sofield procedures $25 \%$, sliding grafts $35 \%$, bone allografts $17 \%$ and autogenous grafts $10 \%$. Recently (Pho et al. 1985) free vascularised fibular grafts have been used and a much higher success rate achieved; this method, however, requires specialised microvascular techniques.

Over the last few years, surgeons using pulsed electromagnetic fields (PEMF) produced by external coils, either alone or in combination with bone grafting, have reported success rates of about $70 \%$ (Bassett, Caulo and Kort 1981; Sutcliffe and Goldberg 1982). This technique required considerable co-operation from the child as the coil was applied for at least 12 hours per day. The average treatment time until union was found to be 7.7 months, and during that period the child was not allowed to bear weight on the affected leg.

We report a series of patients with congenital pseudarthrosis all treated with an implantable electrical

Dennis C. Paterson, MD, FRCS, FRACS, Director and Chief Orthopaedic Surgeon

Department of Orthopaedic Surgery, Adelaide Children's Hospital Inc., 72 King William Road, North Adelaide 5006, South Australia.

Robert B. Simonis, FRCSEd, Consultant Orthopaedic Surgeon, Rowley Bristow Orthopaedic Hospital, Pyrford, Surrey GU22 8UG, England.

Requests for reprints should be sent to $\mathrm{Mr} \mathbf{R}$. B. Simonis

(C) 1985 British Editorial Society of Bone and Joint Surgery $0301-620 X / 85 / 3091 \$ 2.00$ bone-growth stimulator combined with various other surgical procedures. These have been assessed and, from the lessons learnt, we now recommend a standard surgical procedure giving a very good chance of obtaining

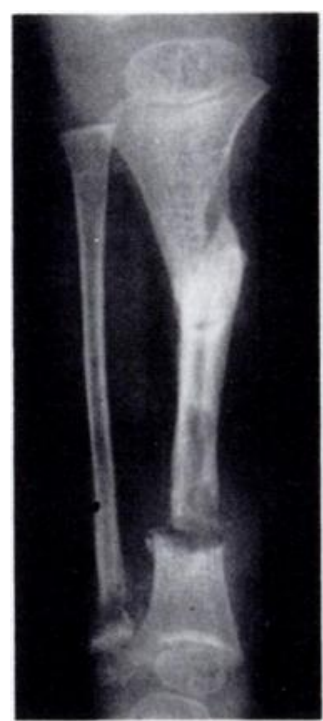

Fig. 1

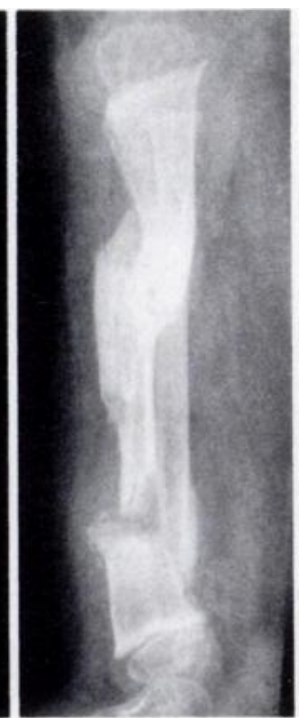

Fig. 2
This boy had a pseudarthrosis at the junction of the upper and middle thirds of the tibia at the age of six months. This was uniting when, at four years of age, he developed a further lesion at the junction of the middle and lower thirds of the tibia.

union. The fibula is divided and the affected area of the tibia excised. The tibial deformity is corrected as fully as possible and then stabilised with an intramedullary rod. An implanted bone-growth stimulator is used to augment bone formation; the titanium cathode is placed in or around the pseudarthrosis. The site is then surrounded by cancellous bone grafts. The leg is protected in plaster until there is clinical and radiological evidence of union; full weight-bearing is allowed. 
This paper is not intended as a scientific assessment of the value of electrical stimulation in congenital pseudarthrosis; it simply presents a series of 25 patients with this condition, of which 20 have united.

\section{MATERIAL AND METHOD}

Over the past 10 years we have treated 25 patients, 16 in Australia and 9 in England. Two patients each had two distinct lesions in separate sites of the same tibia at different times (Figs 1 and 2), so there are in total 27 pseudarthroses in this review. A further patient had a proximal tibial pseudarthrosis from infancy which, after many surgical procedures, had united at the age of four; she later developed a new and separate pseudarthrosis distally, which was treated by the technique to be described. the defect, proceeding through the tibia, the ankle and the os calcis, to emerge through a small incision in the heel. Care must be taken to avoid an inversion, eversion or equinus deformity of the foot. The rod is then hammered upwards into the proximal tibia to just below the growth plate. The distal end of the rod is cut off with a boltcutter at the base of the os calcis. If the tibial diameter is very small a Rush nail can be used; this is inserted through the patellar ligament.

5. The electrical bone-growth stimulator is then inserted. The model used (Osteostim HS.12) has a sealed casing which protects the power source and electronics. The anode is the platinised hemispherical end of the case. The cathode is titanium wire; being attached to a silicone insulated flexi-

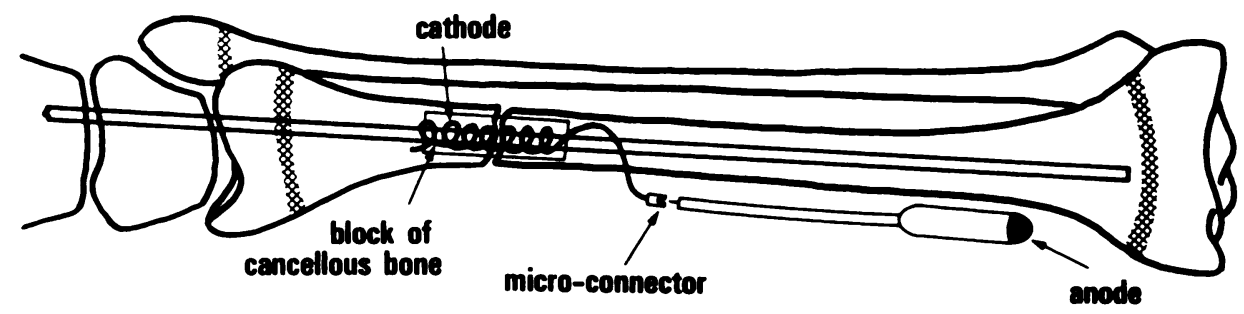

Fig. 3

Technique for insertion of the bone growth stimulator: the cathode is coiled into the form of a helix. If the tibial diameter is too small the coil may be wound around its circumference.

Technique. The operation is complex and should be planned pre-operatively from tracings of recent anteroposterior and lateral radiographs. The amount of diseased bone to be excised should be assessed before the operation so that the tibial deformity can be fully corrected during surgery. The stages of the operation are as follows:

1. The fibula is approached through a lateral incision and divided so as to allow correction of the tibial deformity.

2. The tibia is approached through an anterior vertical incision. The exact amount of bone to be removed varies. Union is most likely when the whole sclerotic segment can be excised leaving good quality bone at each end. Unfortunately, so extensive an excision may leave an unacceptable degree of shortening (a leg-length discrepancy of up to $8 \mathrm{~cm}$ can be allowed). Sometimes the sclerotic segment is so long that some of it has to be left in place. Fortunately union still seems to occur in some of these cases.

3. One of the authors (RBS) considers that it is also important to remove all the abnormal thick fibrous tissue, including periosteum, from the neighbourhood of the defect.

4. Strong fixation is obtained by using an intramedullary rod of the largest possible diameter (a Steinmann pin or Küntscher nail is used). The rod is passed in retrograde fashion, starting at ble lead by a connector, it is removable. This simplifies changing the battery generator should that be necessary. The stimulator provides a direct current of $20 \mu \mathrm{A}$ for at least six months. External monitoring of the current flowing in the bone is possible. The generator is placed beneath the fascia in the calf. New bone forms around the cathode, so its position is critical (Fig. 3). The object is to place as much cathode wire as possible into and around the pseudarthrosis site. The ideal method, if the tibia is wide enough, is to cut a slot in the cortex at the site of the pseudarthrosis (Fig. 4). The cathode is wound into a helix and placed into this slot (Fig. 5). To avoid its displacement one loop of the wire should be fixed under each cortex. The helix should be separated from the intramedullary rod by a sliver of cancellous bone. If the tibia is too small for this the cathode should be wound around the circumference of the tibia, over a length of 1 to $2 \mathrm{~cm}$.

6. The entire area is then packed around with cancellous bone grafts taken from the iliac crest, and the skin is closed with absorbable sutures.

7. A long leg cast is applied and is changed at two weeks; once the skin has healed weight-bearing is encouraged.

After-care. The patient is reviewed at two-monthly intervals. After six months he is re-admitted and, under general anaesthesia, the plaster is removed and union 







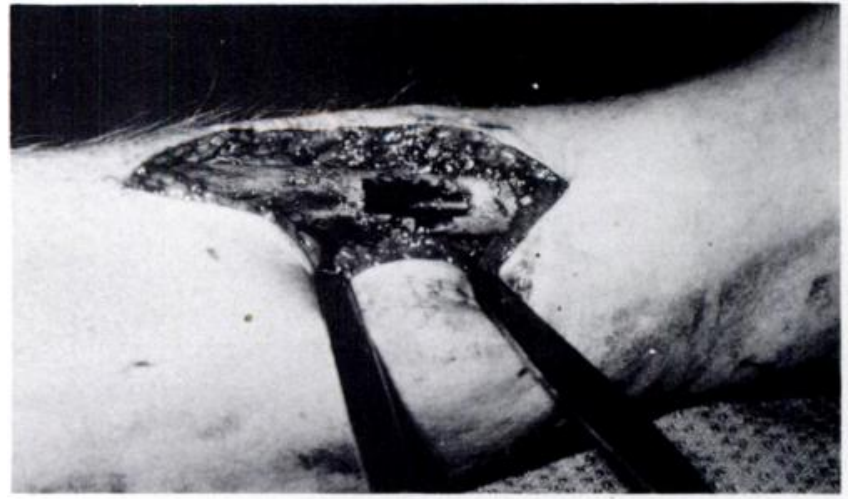

Fig. 4

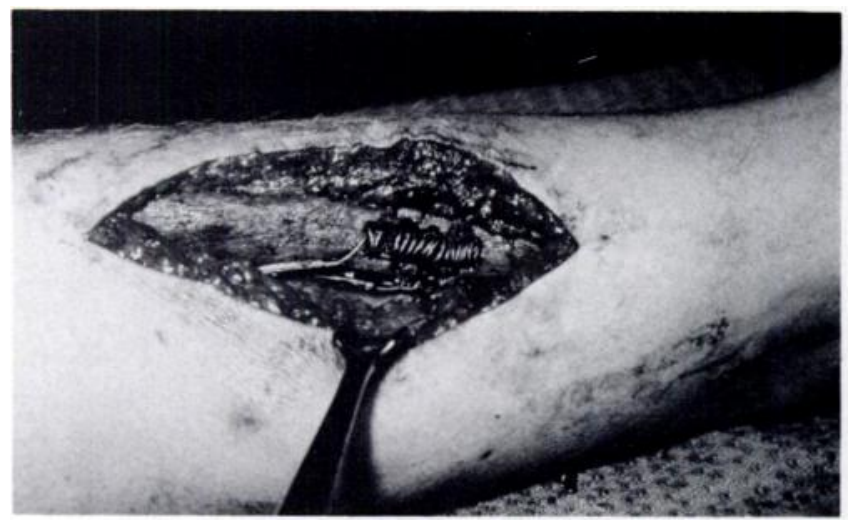

Fig. 5

Intra-operative photographs. Figure 4 -The deformity has been corrected and held with an intramedullary rod. Figure 5-The cathode, formed into a helix. has been inserted into the defect and is separated from the intramedullary rod by cancellous bone

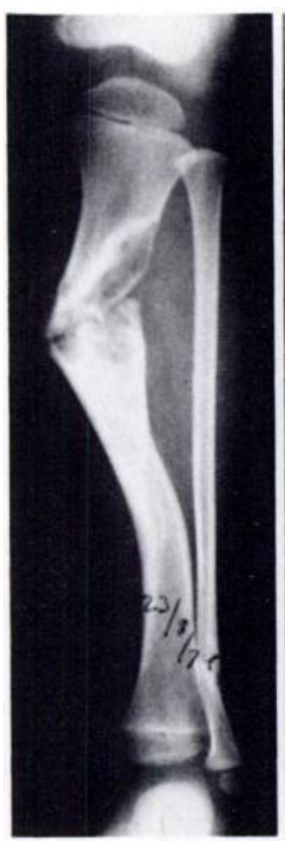

Fig. 6

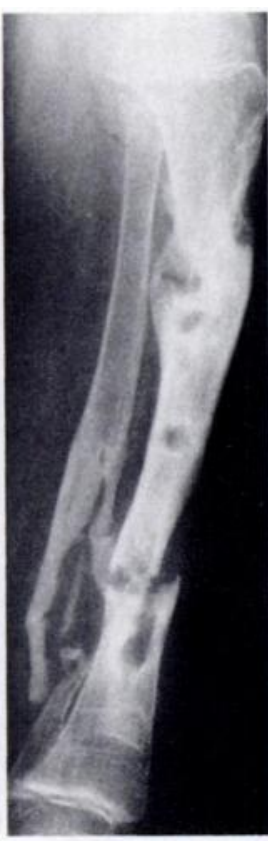

Fig. 7

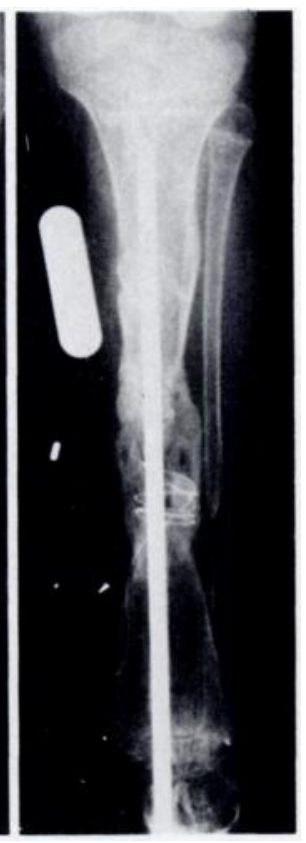

Fig. 8
This girl was born with a cystic defect in the upper tibia. Figure 6 -Aged two years. Figure 7-By the age of seven the upper tibia had, after many operations, united: then she sustained a fracture of the lower tibia. Figure 8-Aged nine years. She required an intramedullary rod, bone grafting and three changes of battery before union occurred. assessed both clinically and radiologically. It is important to test for rotation of the distal tibial fragment around the intramedullary rod.

Initially, it was recommended that the plaster should be exchanged for a weight-relieving caliper once union had occurred (Paterson 1982). Experience has shown that as long as the intramedullary rod remains in place, the leg does not require further protection once the pseudarthrosis has joined.

\section{RESULTS}

Details of the 25 patients (with 27 pseudarthroses) are set out in Table I. There were 16 boys and 9 girls. Neurofibromatosis was present in $48 \%$ of the patients ( 12 of the $25)$. The age at the start of electrical treatment ranged from 18 months to 13 years (mean seven years). Some patients had had up to eight previous surgical attempts at obtaining union. In total there had been 54 previous operations upon these 25 children, mostly bone grafts of the Phemister or McFarland bypass type. Three children had had unsuccessful AO compression plates, and six unsuccessful intramedullary rods; all combined with bone grafting.

Union achieved. Twenty of our 27 pseudarthroses of the tibia $(74 \%)$ have eventually united. However, eight lesions required the insertion of more than one electrical stimulator. Five required two stimulators; four of these united. Two (Cases 19 and 20) have had three stimulators and one of these united (Figs 6, 7 and 8). One lesion (Case 8) had still not united after four attempts with our technique. The time taken for union ranged from 3 to 18 months, with an average of 7.2 months from insertion of the first battery. The follow-up from bony union and freedom from plaster ranged from 6 months to $10 \frac{1}{2}$ years (average of 3.8 years).

Results in relation to classification. Several attempts have been made to classify congenital pseudarthrosis of the tibia (Badgley, O'Connor and Kudner 1952; Nicoll 1969; McBryde and Stelling 1972; Masserman, Peterson and Bianco 1974; Bassett et al. 1981). Difficulties have arisen because the condition includes several different clinicopathological entities, each having a different history and prognosis (Boyd and Sage 1958: Bassett et al. 1981; Boyd 1982). We have used Boyd's classification (Table II) and our results, in terms of this classification, are given in Table III. The commonest group is Boyd's Type II, in which the prognosis-using our method-is reasonable. Twelve united out of 15 ( $80 \%$ success); one of the failures might well have united had it not become grossly infected.

The next most frequent is Type IV, in which a stress fracture occurs through an area of sclerotic bone of normal diameter. These fractures tend to occur when the child is older than those with the other types of pseudarthrosis; they have proved very difficult to treat and only three of our seven united.

The Type III pseudarthroses, with cystic changes in 
Table II. Boyd's classification of congenital pseudarthrosis

$\begin{array}{cl}\text { Type I } & \begin{array}{l}\text { Those born with anterior bowing and a defect in the tibia } \\ \text { (rare) }\end{array} \\ \text { Type II } & \begin{array}{l}\text { Those born with anterior bowing and an hourglass con- } \\ \text { striction. Spontaneous fracture occurs usually before two } \\ \text { years of age. This type is often associated with neurofibro- } \\ \text { matosis. }\end{array} \\ \text { Type III } & \begin{array}{l}\text { Those developing in a bone cyst, often at the junction of } \\ \text { the upper and lower third of the tibia. Anterior bowing } \\ \text { may precede or follow a fracture }\end{array} \\ \text { Type IV } \quad \begin{array}{l}\text { Those originating in a sclerotic segment of tibia without } \\ \text { any narrowing or fracture; the medullary canal is partially } \\ \text { or completely obliterated. This type progresses to a stress- } \\ \text { type fracture which fails to unite }\end{array} \\ \text { Type V } \quad \begin{array}{l}\text { Those who also have a dysplastic fibula; these children } \\ \text { develop pseudarthrosis later }\end{array} \\ \text { Type VI } \quad \begin{array}{l}\text { Those with an interosseous neurofibroma or schwannoma } \\ \text { (very rare) }\end{array}\end{array}$

Table III. The present series according to Boyd's classification

\begin{tabular}{lccc}
\cline { 2 - 3 } N & Number & Successful union & Failure \\
\hline Type II & 1 & - & 1 \\
Type III & 15 & 12 & 3 \\
Type IV & 2 & 2 & - \\
Type V & 7 & 3 & 4 \\
Type VI & 2 & 2 & - \\
\hline
\end{tabular}

the tibia, usually have a fair prognosis and both our cases united. Type $\mathbf{V}$ cases initially have a normal tibia and dysplastic fibula, and develop a pseudarthrosis of the tibia later; they also appear to have a reasonable prognosis and here again both our cases united.

Irrespective of the classification used, the same surgical technique has been applied in all the cases presented.

\section{FAILURES AND COMPLICATIONS}

Reasons for failure. The reasons for failure merit scrutiny. The commonest causes were: inadequacy in the correction of the anterior bowing of the tibia; poor internal fixation; incorrect placement of the cathode; and extensively diseased bone. In two cases the length of diseased bone was too great to expect a useful limb to result with our technique-over half the length of the tibial shaft was either missing or avascular. In one of these two cases a vascularised fibular graft was taken from the other leg and union was then achieved. In the other (Fig. 9), the leg was eventually amputated. We fully appreciate that there are cases in which a vascularised graft or amputation are the only possibilities.

Infection. Two cases became infected after operation despite the reported bacteriostatic effect of electrical stimulation (Marino and Becker 1977; Becker and
R. B. SIMONIS

Spadaro 1978, 1979). In one case the infection cleared with chemotherapy; a second electrical stimulator was then inserted and bony union proceeded uneventfully. In the other case gross infection developed and all foreign material had to be removed; although the discharge ceased after six months, the pseudarthrosis persisted. We now use prophylactic antibiotics in all cases.

Shortening. Most of our patients had shortening of the affected leg even after union had been achieved. However, it does seem possible that bone growth can increase after union and compensate for the shortening. The younger the child at bony union the better the chance of achieving an acceptable length. We agree with Morrissy et al. (1981) that after 13 years of age accelerated bone growth tails off, and even if union has been achieved gross shortening (over $10 \mathrm{~cm}$ ) may lead the surgeon to offer amputation as a better alternative. Two of our younger patients both had nearly $10 \mathrm{~cm}$ of shortening after excision of the pseudarthrosis; both tibiae joined and the leg-length discrepancy has now almost corrected. One was nine years old at union, and two and a half years after her operation she had recovered all but $2.4 \mathrm{~cm}$ of the discrepancy. The other was eight years old when her fracture united, and four years after operation her legs were almost equal in length.

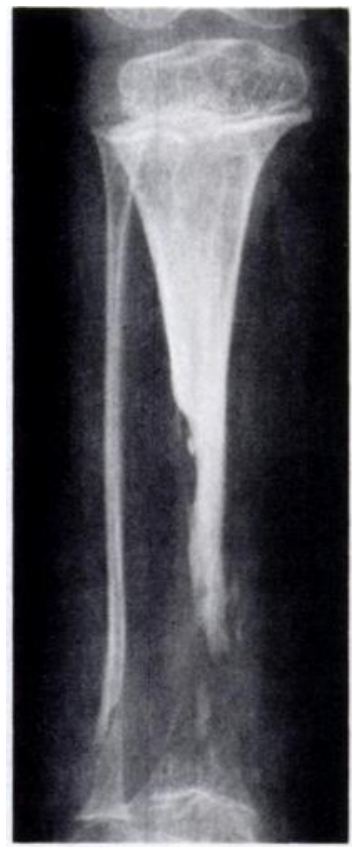

Fig. 9

The tibia in this patient was so extensively involved that amputation was necessitated.

Deformity. Two of our patients (Cases 17 and 21) developed valgus deformity at the ankle after union. It was assumed that this resulted from damage to the lower tibial epiphysis. One (Case 17) eventually required an ankle fusion; in the other (Case 21) valgus was still increasing at the latest review. 

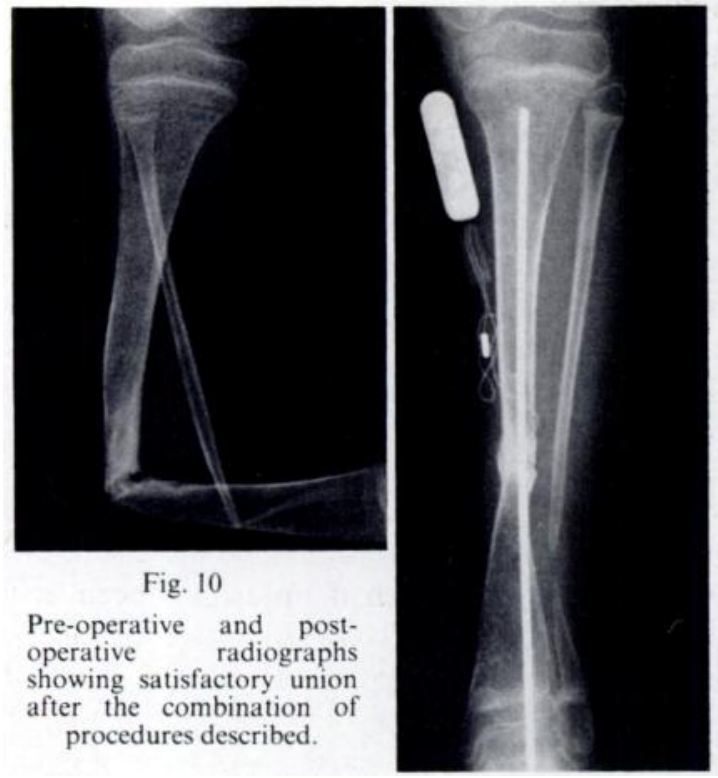

Fig. 11

\section{DISCUSSION}

Association with neurofibromatosis. There is unquestionably an association between neurofibromatosis and congenital pseudarthrosis of the tibia (Ducroquet 1937; Barber 1939; Aegerter 1950; Jaffe 1958; Sofield 1971; McBryde and Stelling 1972; McElhannon 1975). Twelve of our patients had neurofibromatosis, seven from Boyd's Type II, four from Type IV and one from Type V. Ten of these progressed to union, suggesting that the presence of neurofibromatosis does not necessarily point to a bad prognosis.
Age. There was a wide age-range among the children starting our regime. One child united at two years of age and three others were successfully treated under the age of four years. These results emphasise that age at the time of operation is less critical than previously believed (Sofield 1971; Masserman et al. 1974; Hardinge 1972; McElhannon 1975). Nevertheless the younger the child at union the better will be the chance of equalisation of leg length.

Management. The treatment of congenital pseudarthrosis of the tibia has long been recognised to be very difficult (Hardinge 1972). Latterly, Bassett et al. (1981) and Sutcliffe and Goldberg (1982), using pulsed electromagnetic fields-sometimes combined with surgeryhave reported an overall success rate of over $70 \%$. The success rate in our series of $74 \%$ ( 20 out of 27 cases) is comparable with theirs. However, they use a weightrelieving splint and they need co-operation from the patient. With our technique weight-bearing is encouraged and patient co-operation is not involved, so that it is particularly suitable for young children.

Over the past nine years we (DCP and RBS) have arrived independently at the conclusion that for the best chance of permanent union five specific features are needed in the surgical management (Figs 10 and 11). As these were only recognised after our earlier cases had been treated, not all our patients have had what we now consider to be the ideal management. The five features are as follows.

1. Correction of the tibial deformity. It is always possible to correct the characteristic anterior bowing of the tibia completely, providing the fibula is divided. In order to

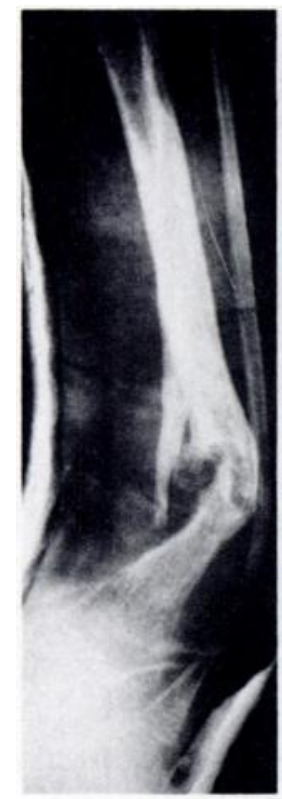

Fig. 12

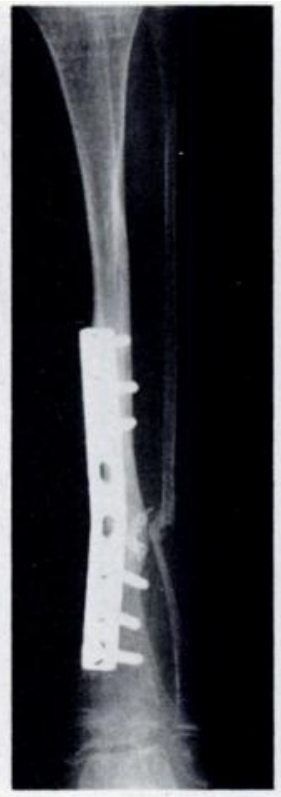

Fig. 13

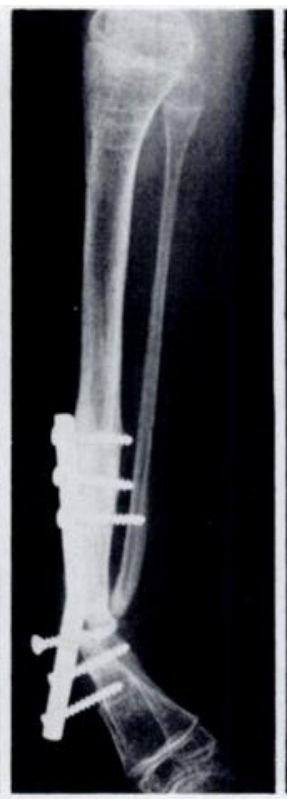

Fig. 14

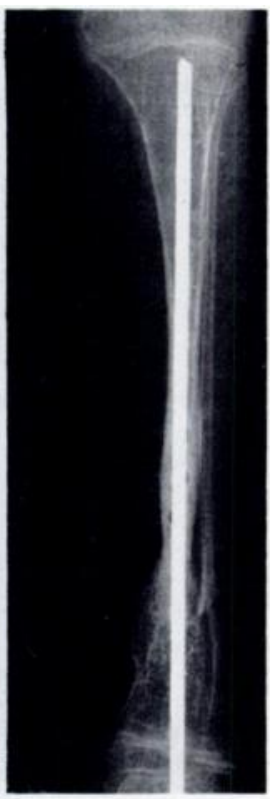

Fig. 15

The failure of plating. Figure 12-This patient has a long-standing pseudarthrosis of the tibia despite many operations. Figure 13-An AO compression plate combined with electrical stimulation and bone grafting was thought to have achieved union. Figure 14 -Eighteen months later clearly union had not occurred. Figure is-Subsequently union did occur after correction of the deformity with an intramedullary rod and bone grafting. 


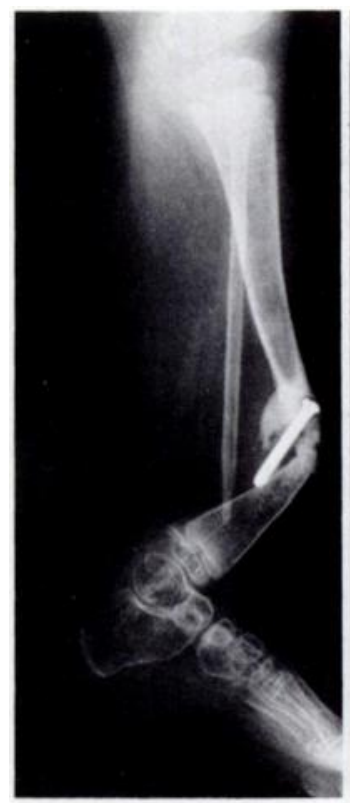

Fig. 16

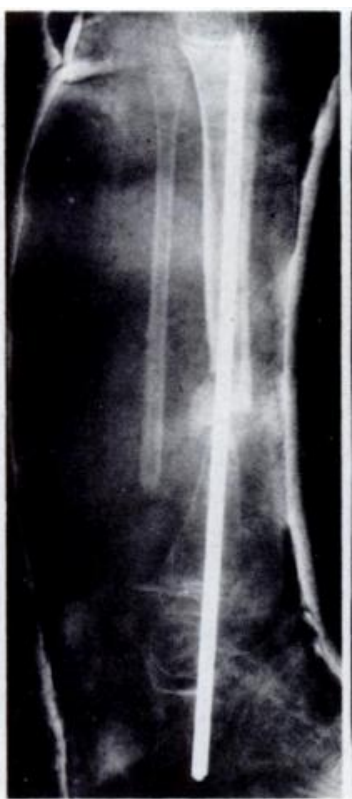

Fig. 17

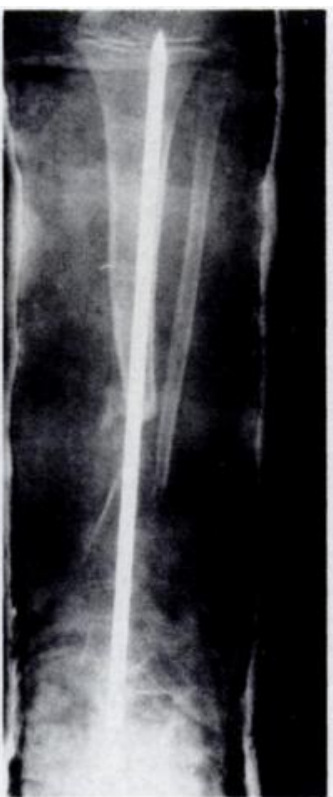

Fig. 18

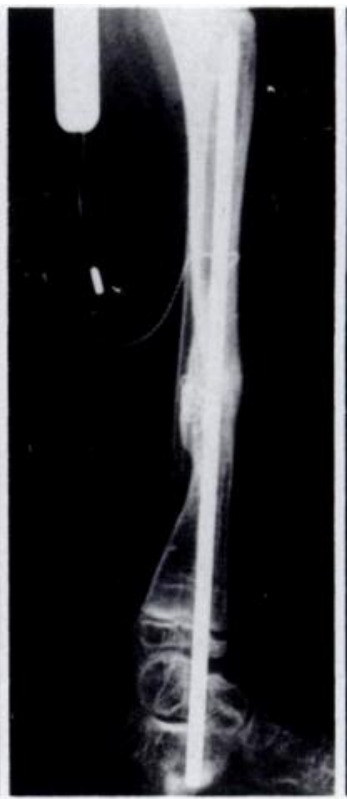

Fig. 19

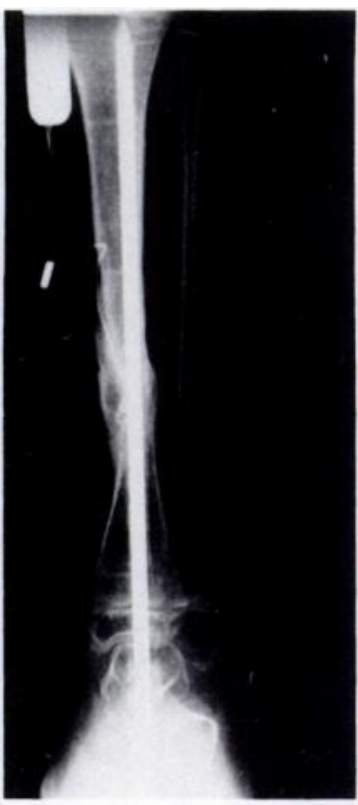

Fig. 20

The value of electrical stimulation. Figure 16- This eight-year-old girl had had eight previous operations. Figures 17 and 18 - Four months after inserting an intramedullary rod and bone grafts there was no evidence of clinical or radiological union. Figures 19 and $20-$ Three months after insertion of a stimulator and further bone graft there is solid union.

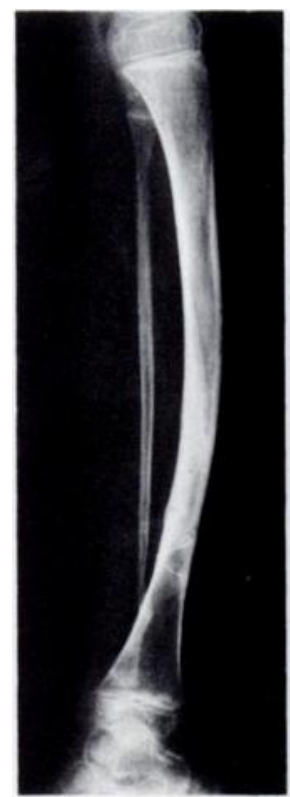

Fig. 21

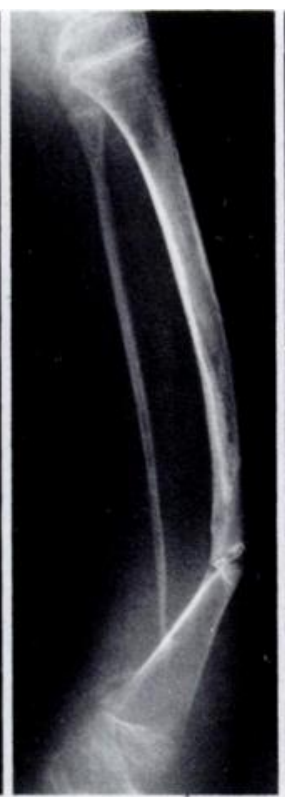

Fig. 22

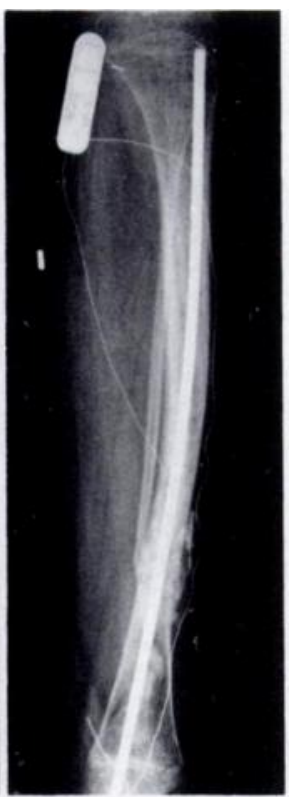

Fig. 23

The importance of an intramedullary rod. Figure $21--\ln$ this patient electrical treatment alone (no intramedullary rod was inserted) achieved union when he was aged eight years. Figure 22 - Three years later the bone refractured. Figure 23-Eventually, with the combined technique union occurred. 


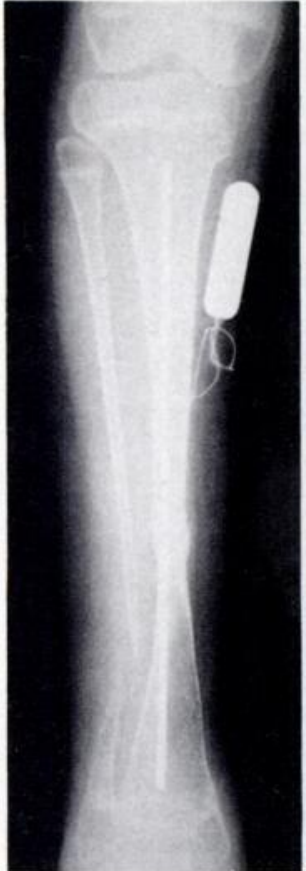

Fig. 24

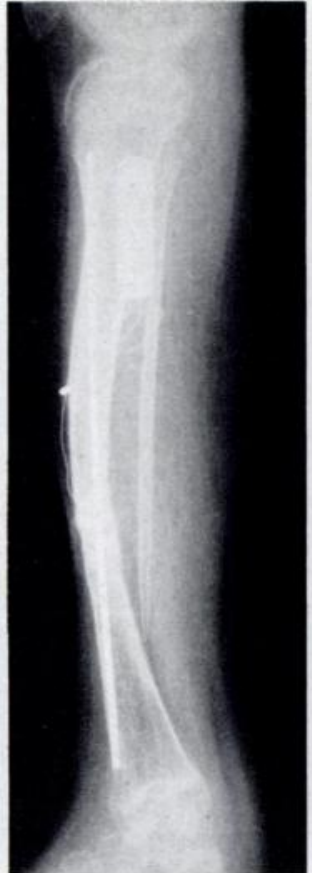

Fig. 25

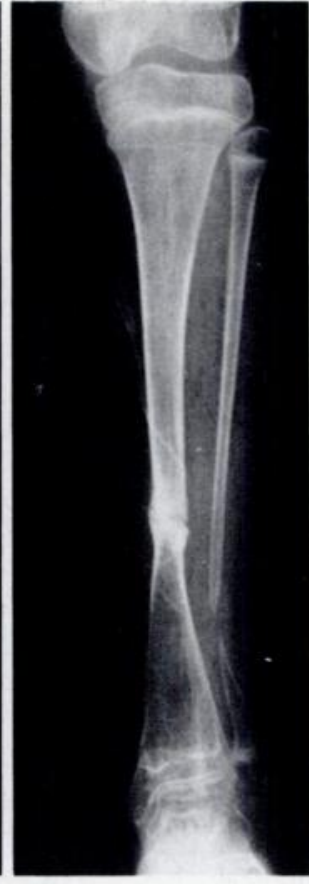

Fig. 26

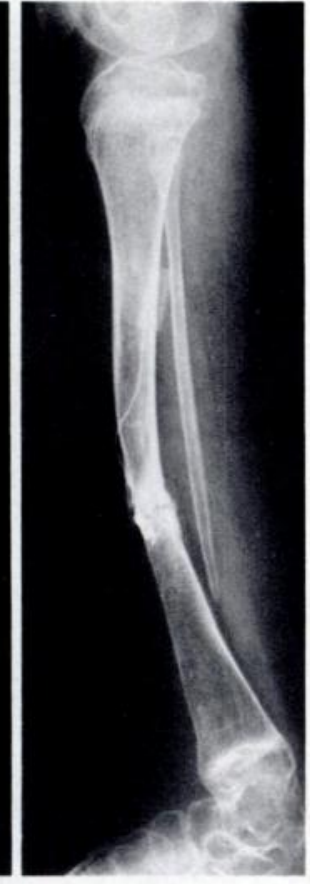

Fig. 27

The danger of removing the rod too soon. Figures 24 and 25 -In this patient union had occurred following the combined procedure we advocate. Figures 26 and 27 -But soon after the rod was removed. the bone refractured.

achieve a straight tibia, the saw-cuts resecting the tibial lesion should be correctly calculated from pre-operative tracings of recent radiographs. Five of our earlier cases had inadequate correction of the bowing, which then had to be held with too short an intramedullary rod because a larger one would not fit; four of these cases did not unite. 2. Adequate intramedullary fixation. As well as occurring when the intramedullary rod was too short or too thin, failures also occurred when AO compression plating was used instead of intramedullary fixation. Four patients had electrical stimulation and bone grafting combined with AO compression plating; none of these united and in all four the plate eventually broke (Figs 12 to 15). These four cases illustrate that electrical stimulation alone is usually not enough to promote union and that adequate internal fixation with as large an intramedullary rod as possible is essential-a plate is not strong enough.

3. Electrical stimulation. One of our early cases (Figs 16 to 20) illustrates the importance of electrical stimulation. The deformity was adequately corrected, held by firm intramedullary fixation and grafted with cancellous bone, but electrical stimulation was not used. There was no sign of union at four months; however, with electrical stimulation and the addition of bone grafts union occurred in a further three months. Although there is no scientific proof from this paper that electricity aids union, we would now be very reluctant to treat congenital pseudarthrosis without an electrical bone-growth stimulator.

The electrical generator we use has an active life of six months and can be removed simply by separating the stainless steel lead from the connector attached to the cathode, which is left in situ permanently. The child and parents must be told from the outset that union will take many months and that several operations may sometimes be necessary. If radiological union is not established after six months and the overall alignment of the tibia remains satisfactory, a new stimulator and more cancellous bone graft should be added. Eight cases needed the insertion of more than one stimulator before they achieved sound union.

4. Cancellous bone graft. It was considered that a bone graft was necessary in all cases. This should be autogenous and is best taken from the iliac crest.

5. Long-term internal fixation. One of our cases (Figs 21 to 23) illustrates the value of long-term intramedullary internal fixation. Although the tibia joined initially after electrical stimulation and bone grafting alone, it refractured after three years. It has now been united for two and a half years after further surgery, which this time included rod fixation.

The intramedullary rod should not be removed until skeletal maturity. If problems such as protrusion arise, the rod may be extracted after the tibia has completely remodelled, which usually occurs some three to four years after bony union. In two cases (Figs 24 to 27), the tibia refractured after the intramedullary rod had been removed prematurely. In one other case the tibia remains united, but is once again bowing progressively since removal of the rod.

Conclusions. We believe that with congenital pseudarthro- 
sis of the tibia the combination of excision of the diseased area, correction of the deformity, intramedullary fixation, bone grafting and electrical stimulation offers a good chance of achieving union; all five aspects of the treatment are fundamental. However, no technique with a failure rate of nearly $30 \%$ can be accepted as definitive and ours has been, and is being, modified in the light of progress and results.

We wish to acknowledge the help and co-operation that we have received from our orthopaedic surgical colleagues: in Australia, E. H. Bates, C. A. Cass, K. R. Daymond, A. F. McSweeny, F. W. Marsden, M. B. Menelaus, J. H. Rush, J. G. Sweeney, F. B. Webb; in England, R. Q. Crellin, R. A. Denham, J. A. Fixsen, R. Owen, D. A. Reynolds, P. J. Webb; and in Hong Kong. J. Y. C. Leong. We also wish to thank $\mathrm{Mr}$ W. Murphy for his help with the manuscript, and the clinical photographers, Mr B. J. Greiger of the Adelaide Children's Hospital, and Mrs J. Morgan of the Rowley Bristow Orthopaedic Hospital.

\section{REFERENCES}

Aegerter EE. The possible relationship of neurofibromatosis, congenital pseudarthrosis and fibrous dysplasia. J Bone Joint Surg $[\mathrm{Am}]$ $7950: 32-\mathbf{A}: 618-26$.

Badgley CE, O'Connor SJ, Kudner DF. Congenital kyphoscoliotic tibia. J Bone Joint Surg [Am] 1952;34-A:349-71.

Barber CG. Congenital bowing and pseudarthrosis of the lower leg: manifestations of von Recklinghausen's neurofibromatosis. Surg Ginecol Obstet 1939:69:618-26.

Bassett CAL, Caulo BSN, Kort J. Congenital "pseudarthroses" of the tibia: treatment with pulsating electromagnetic fields. Clin Orthop $1981: 154: 136-49$.

Becker RO, Spadaro JA. Treatment of orthopaedic infections with electrically generated silver ions: a preliminary report. J Bone Joint Surg $[$ Am $]$ 1978;60-A :871-81.
Becker RO, Spadaro JA. Experience with low-current/silver electrode treatment of nonunion. In: Brighton CT, Black J, Pollack SR, eds. Electrical properties of bone and cartilage: experimental effects and clinical applications. New York: Grune \& Stratton, 1979: 631-8.

Boyd HB, Sage FP. Congenital pseudarthrosis of the tibia. $J$ Bone Joint Surg $[A m] 1958 ; 40-\mathbf{A}: 1245-70$.

Boyd HB. Pathology and natural history of congenital pseudarthrosis of the tibia. Clin Orthop 1982;166:5-13.

Ducroquet R. A propos des pseudarthroses et inflexions congénitales du tibia. Mém Acad Chir 1937;63:863-8.

Hardinge K. Congenital anterior bowing of the tibia: the significance of the different types in relation to pseudarthrosis. Ann $R$ Coll Surg Engl 1972;51:17-30.

Jafie H. Tumours and tumorous conditions of bones and joints. London: Kimpton, 1958:252.

McBryde AM Jr, Stelling FH. Infantile pseudarthrosis of the tibia. J Bone Joint Surg [Am] 1972:54-A:1354-5.

McElhannon FM Jr. Congenital pseudarthrosis of the tibia. South Med J 1975;68:824-7.

Marino AA, Becker RO. Electrical osteogenesis: an analysis. Clin Orthop 1977; 123:280-2.

Masserman RL, Peterson HA, Bianco AJ Jr. Congenital pseudarthrosis of the tibia: a review of the literature and 52 cases from the Mayo Clinic. Clin Orthop 1974:99:140-5.

Morrissy RT, Riseborough EJ, Hall JE. Congenital pseudarthrosis of the tibia. J Bone Joint Surg [Br] $1981 ; 63-B: 367-75$.

Nicoll EA. Editorial: infantile pseudarthrosis of the tibia. $J$ Bone Joint Surg [Br] 1969:51-B:589-92.

Paterson DC. Clinical use of the Osteostim, an implanted bone growth stimulator, for impaired bone healing. Am Acad Orthop Surg Instr Course Lect 1982;31:103-13.

Pho RWH, Levack B, Satku K, Patradul A. Free vascularised fibular graft in the treatment of congenital pseudarthrosis of the tibia. J Bone Joint Surg [Br] 1985;67-B:64-70.

Sofield HA. Congenital pseudarthrosis of the tibia. Clin Orthop $1971 ; 76: 33-42$.

Sutcliffe ML, Goldberg AAJ. The treatment of congenital pseudarthrosis of the tibia with pulsing electromagnetic fields: a survey of 52 cases. Clin Orthop 1982;166:45-57. 